\title{
FOREWORD, 1937
}

San Diego has long been in need of a compact, comprehensive guide book which would not only be of aid to the thousands of annual tourists, but also of interest to residents desirous of knowing the full range of San Diego's colorful history. In the past this need has been satisfied either by voluminous works, far too bulky for handy reference, or by small brochures, tantalizing in their brevity.

It is no easy matter to select well from the thousands of relevant and irrelevant facts which have gone into the making of history here during almost four centuries. That so many have been included, and woven into so compact a form, is this book's chief merit, and will far outweigh, I believe, any individual group interests which might be disturbed by particular omissions. The necessity of presenting a close-knit picture of the total scene has been at all times the compilers' principle, and a perusal of this volume must convince the reader of that constant attention.

San Diego is becoming increasingly aware of its historical heritage -the knowledge that it was the birthplace of California. All historical growths have been strengthened by their traditional backgrounds, and San Diego is more than blessed with its centuries of ever-varying cultural influences. This book is a record of all that, as well as of the city's present development and potentialities as a commercial and industrial center. It is for this reason that the Historical Society has undertaken the sponsorship of SAN DIEGO: A California City. It has historical, and, we believe, genuine literary value.

The work of the San Diego Federal Writers' Project must not be judged too lightly because this book can be quickly read. In its final form it is the composite effort of many individuals - a cooperative venture-a social undertaking in the finest sense of the word. More than a year and a half was spent in compiling facts, weighing evidence, writing and rewriting the material. That it shows a unity of purpose and an evenness of writing is a credit to the spirit of the whole Writers' Project whose individual members were able to subordinate personal tastes and interests to the accomplishment of a good job.

\author{
LEROY A. WRIGHT, President \\ San Diego Historical Society.
}




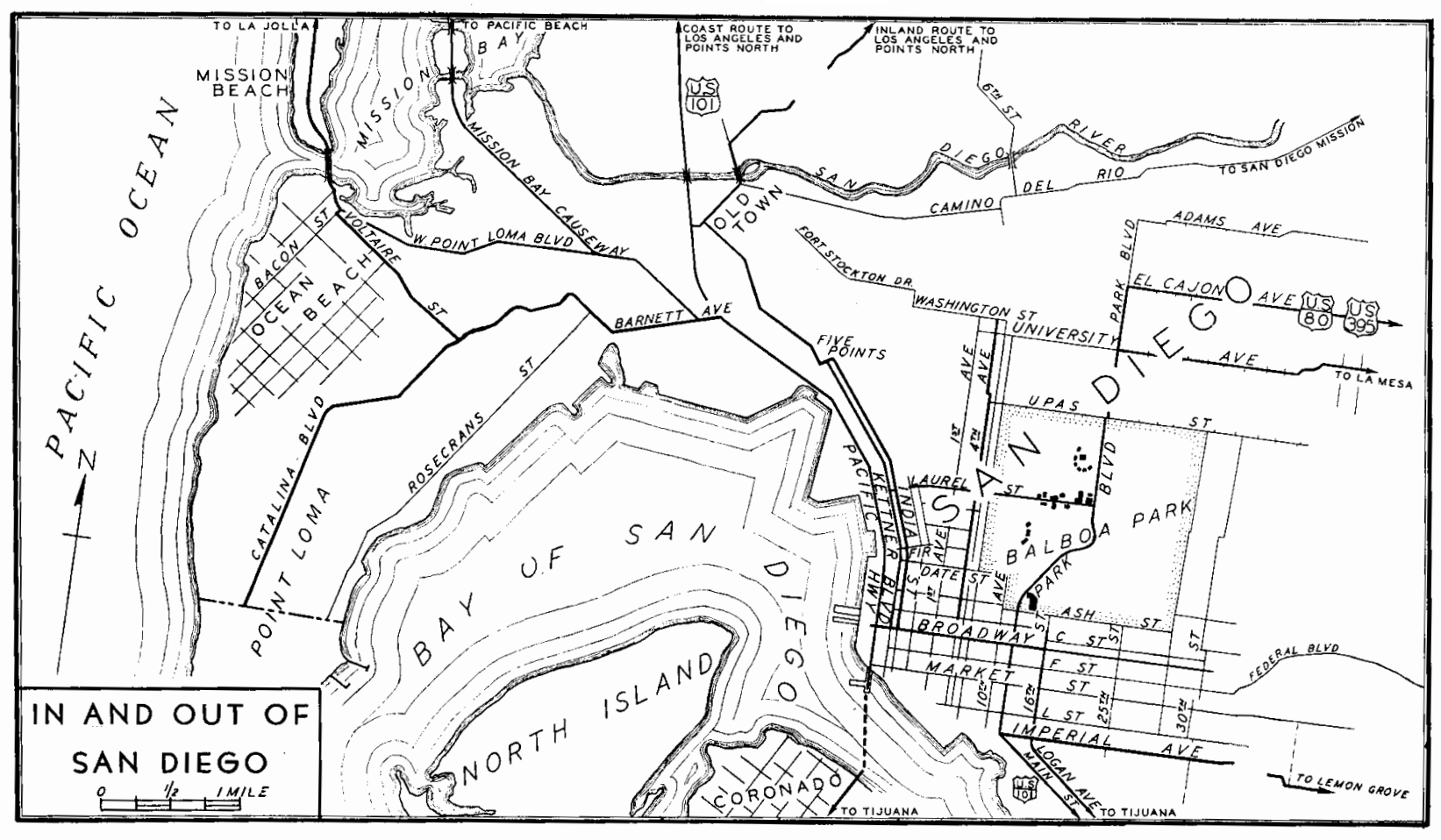

